\title{
Isolated Blunt Traumatic Diaphragmatic Rupture in a Case of Situs Inversus
}

\author{
Raiees Ahmad*, Malik Suhail, Alfer Nafae, Qayoom Khan, Pervaze Salam, \\ Shahnawaz Bashir, Yawar Nisar \\ Department of Surgery, Government Medical College, Srinagar, Jammu and Kashmir, India \\ Email: mallahraiees@gmail.com
}

Received 17 February 2015; accepted 16 March 2015; published 17 March 2015

Copyright (C) 2015 by authors and Scientific Research Publishing Inc.

This work is licensed under the Creative Commons Attribution International License (CC BY). http://creativecommons.org/licenses/by/4.0/

\begin{abstract}
Situs inversus, a very rare congenital anomaly of reversal site of thoracic and abdominal organs, can be very problematic to surgeon while dealing with a case of trauma in emergency. Surgical procedures are considered difficult, complex and more challenging in patients with this condition due to the anatomical difference and position of organs. We came across an interesting and very rare case of isolated blunt traumatic diaphragmatic injury in a case of situs inversus. Traumatic injuries of the diaphragm are uncommon and isolated blunt traumatic injuries of diaphragm are very rare. Our case is very unique of its kind of situs inversus with isolated right sided diaphragmatic rupture in a 60 -year-old male patient presenting 4 hours after blunt trauma to chest and abdomen.
\end{abstract}

Keywords

Situs Inversus, Isolted Diaphragmatic Injury, Blunt Trauma

\section{Background}

Situs inversus is a very rare congenital anomaly of reversal site of thoracic and abdominal organs [1]. It can be partial (only one cavity affected) or total (abdominal and thoracic organs affected). This anatomical anomaly usually does not affect survival of patient and is not considered pre-malignant [2] [3] condition, and is usually diagnosed incidentally. Surgical procedures are considered difficult in patients with this condition due to the anatomical difference and position of organs. Liver is on left side and the orientation of the hepatic vessels is reversed, and the upper right quadrant contains the spleen and stomach. Although the surgical procedures in patients with situs inversus have more complex situations and are technically challenging, the operations can be successfully performed even with extensive trauma major injuries.

\footnotetext{
${ }^{*}$ Corresponding author.
}

How to cite this paper: Ahmad, R., Suhail, M., Nafae, A., Khan, Q., Salam, P., Bashir, S. and Nisar, Y. (2015) Isolated Blunt Traumatic Diaphragmatic Rupture in a Case of Situs Inversus. Surgical Science, 6, 133-137. 
Traumatic injuries of the diaphragm are uncommon and isolated blunt traumatic injuries of diaphragm are very rare. It is generally considered to be a marker of severe trauma. In patients with blunt trauma, traumatic injuries of the diaphragm represent only $0.8 \%$ to $1.6 \%$ of the total lesions observed in these patients [4]. There has been a predominance of lesions of the left hemidiaphragm, with a ratio of 25:1. Blunt trauma to the abdomen increases the transdiaphragmatic pressure gradient between the abdominal compartment and the thorax. There should be a high index of suspicion for diaphragmatic injury in those patients who are victims of road traffic accidents, especially if they have suffered frontal or lateral impacts, resulting in severe thoraco-abdominal trauma. Road traffic collisions or lateral intrusions into the vehicle or direct impact on chest are the most frequent causes of diaphragm rupture [5]-[7]. Isolated traumatic rupture of diaphragm in a patient with situs inversus is very uncommon.

We came across an interesting case of isolated traumatic diaphragmatic injury in a patient with situs inversus who had sustained a road traffic accident. Such case of situs inversus with isolated traumatic right sided diaphragmatic rupture is a very rare case of its kind.

\section{Case Report}

A 60-year-old male patient presented to surgical casualty on 05/03/13 with chief complaints of pain right upper abdomen and breathlessness 4 hours after sustaining a road traffic accident with impact on right side head, chest and abdomen. On examination patient was conscious, oriented and had tachypenia with normal airway. Patient had pulse of 88 beats/minute, BP of 130/90 mmHg, respiratory rate of 24 breaths/minute. Chest examination showed abrasions on right side chest, sever tenderness over right lower chest with decreased air entry on right lower chest. Cardiovascular examination revealed apical impulse and normal heart sounds on right side of chest with no added sounds. Abdominal examination revealed non-distended abdomen with guarding and tenderness over right hypochondrium and epigastrium. Local examination showed small laceration on right side face which required stitching, abrasions on right chest and right leg. Clinically it seemed to be a case of dextrocardia with right sided pneumothorax/heamothorax. All routine baseline investigations with other specific relvent investigations were done. FAST scan did not reveal anything significant. Chest X-ray showed cardiac shadow on right side and no other significant finding. CECT chest and abdomen detected an isolated right sided diaphragmatic rupture with herniation of part of transverse colon into right pleural cavity (Figure 1). Patient was explored on same day by upper midline laparotomy incision and thorough inspection of peritoneal cavity was done. Patient was found to have situs inversus with an isolated $2+3 \mathrm{~cm}$ perforation in right hemidiaphragm and herniation of tranverse colon into right hemithorax (Figure 2). Rest all of the viscera and solid organs were grossly normal. After reduction of hernia contents back into abdominal cavity, repair diaphragmatic rent was done with 2-0 silk and right side intercoastal tube thorcostomy was done. Postoperative period was uneventful, chest tube was removed on $3^{\text {rd }}$ postoperative day and patient was discharged on $4^{\text {th }}$ postoperative day with advise to follow surgical OPD regularly.

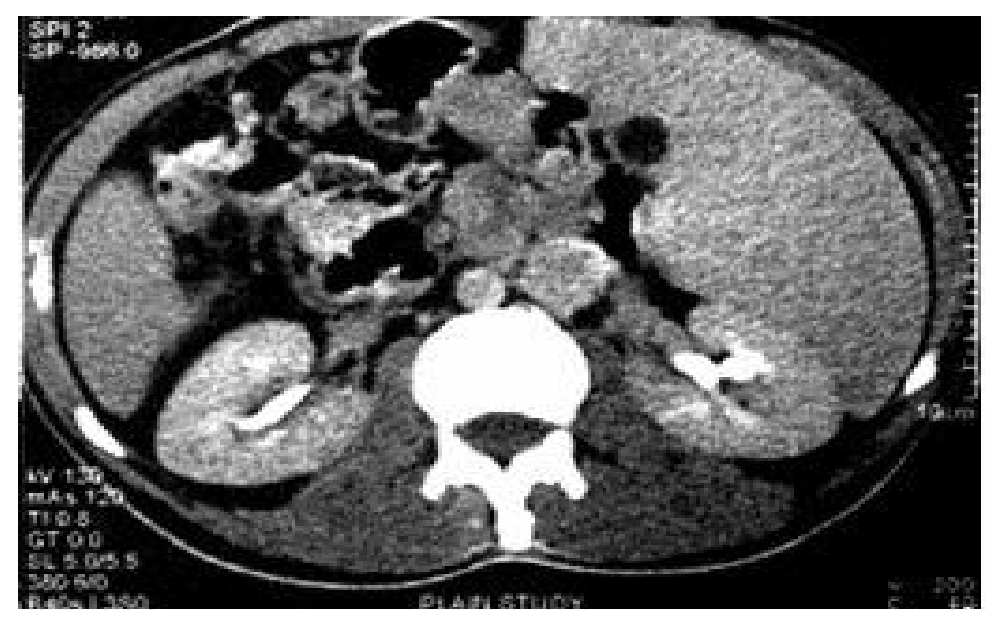

Figure 1. CECT abdomen showing situs inversus with diaphragmatic rupture. 


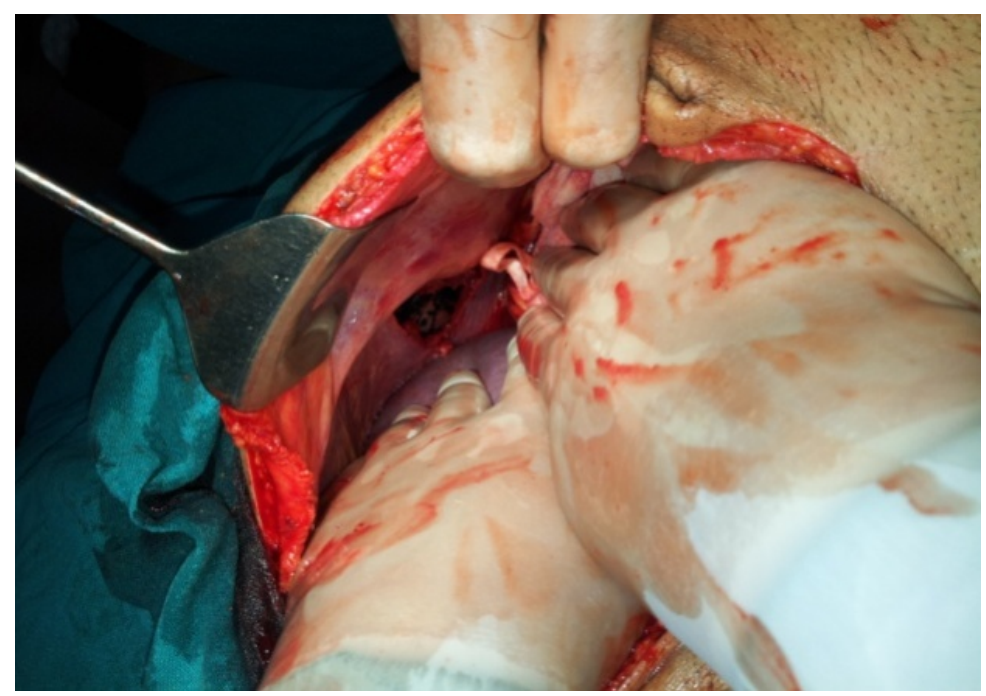

Figure 2. Intra operative picture showing a rent in right hemi-diaphragm with situs inversus.

\section{Discussion}

Traumatic injuries of the diaphragm are uncommon and isolated blunt traumatic injuries of diaphragm are very rare with incidence of only $0.8 \%$ to $1.6 \%$ in reported cases [4]. An isolated blunt traumatic diaphragmatic injury in a case of situs invesus is extremely uncommon. We came across an interesting case of isolated blunt traumatic diaphragmatic injury in a patient with situs inversus following road traffic accident.

Situs inversus is a very rare congenital anomaly of reversal site of thoracic and abdominal organs [1] can be partial (only one cavity affected) or total (abdominal and thoracic organs affected). Surgical procedures are considered difficult, complex and more challenging in patients with situs inversus condition due to the anatomical difference and position of organs. Although the surgical procedures in patients with situs inversus are technically challenging, the operations can to be successfully performed even with extensive trauma major injuries. Traumatic injuries of the diaphragm are uncommon and these injuries should be suspected in those patients who are victims of road traffic accidents, especially if they have suffered frontal or lateral impacts, resulting in severe thoracoabdominal trauma. Road traffic collisions or lateral intrusions into the vehicle or direct impact on chest are the most frequent causes of diaphragm rupture [4]-[6]. Direct impact can cause depress the side of the rib cage, and causes a tear in the diaphragm rib attachments, or transverse rupture of the diaphragm [8]. Grimes [9] described the 3 phases of diaphragmatic rupture. (A) The acute phase is at the time of the injury to the diaphragm. (B) The delayed phase is associated with transient herniation of the viscera leading to absence or intermittent non specific symptoms. (C) The obstruction phase denotes complication of a long standing herniation, manifesting as obstruction, strangulation and ruptured. (D) The organs that herniate into the thoracic cavity include the stomach, spleen, colon, small bowel and liver.

Our case of isolated right diaphragmatic rupture presented 4 hrs after a road traffic accident with herniation of tranverse colon into right pleural cavity. Diaphragmatic ruptures usually occur at the central tendon or at the junction between the tendinous and muscular parts of the diaphragm mostly on left side (65\% - 85\%) compared to the right side $(15 \%-35 \%)$ and few patients have rupture of both domes (1\% - 12\%) [10] [11] due to protective effect on right side is due to the protection offered by the liver on the right side, under-diagnosis of rupture on the right side, and weakness of the left hemidiaphragm. Rupture of diaphragm in our case was on right side as patient had situs inversus and proposed protective effect was on left hemidiaphragm. The clinical presentation is defined by the overall assessment of the patient with multiple injuries. In most cases traumatic ruptures of the diaphragm occur with other associated vascular and visceral injuries [12]. Due to co existing injuries and the silent nature of diaphragmatic ruptures, the diagnosis can sometimes be missed in the acute phase and may present later on. Patients usually present with non specific symptoms and may complain of chest pain, abdominal pain, dyspnoea, tachypnoea, cough, nausea and vomiting. A high index of suspicion is the key for the correct diagnosis. Our patient of road traffic accident presented with dysnea and chest pain 4 hours after road traffic accident 
with tenderness on right lower chest and decreased breath sounds on right lower chest.

No single investigation can provide a reliable diagnosis of diaphragmatic rupture in a patient. The diaphragmatic injury is suspected in any patent with blunt thorocoabdominal trauma when any hemidiaphragm is not seen or is not in the correct position in a chest radiograph. The specific signs on plain radiograph include, a marked elevation of the hemidiaphragm, unclear diaphragmatic borders and abnormal gas pattern on plain $\mathrm{X}$-rays, an intrathoracic herniation of abdominal viscera, the "collar sign", demonstration of a nasogastric tube tip above the diaphragm [13]. The diagnosis is based largely on high clinical suspicion and radiological evidence. The surgical treatment performed includes hernia reduction, pleural drainage and primary repair of the diaphragmatic defect. This may be performed either by an open laparotomy or thoracotomy or by minimally invasive procedures like laparoscopy or thoracoscopy. There are various surgical approaches for diaphragmatic hernias repair which includes primary repair with non-absorbable simple sutures in most cases, and the use of mesh is reserved for chronic and large defects. Polytetrafluoroethylene, polyethylene terephthalate, and polypropylene are the most common materials used to repair large diaphragmatic defects that are not amenable to primary repair.

We explored the patient by a midline laparotomy incision, reduced the diaphragmatic hernia, primarily closed the diaphragmatic defect with 2-0 silk and provided right intercoastal tube drainage. Patient recovered uneventfully. Ramon Vilallonga, Vicente Pastor, Laura Alvarez et al. [14] reported a case of right sided diaphragmatic injury in a patient with history of fall from 12 feet with blunt trauma to chest and abdomen. Patient was operated in emergency, repair of right hemidiaphragm and packing of liver laceration was done and patient recovered uneventfully. Gati Ebrahimi and Frank W. Bloemers [15] reported a case of delayed rupture of diaphragm in a young male patient following a fall with impact on right side of chest and patient had herniation of liver into right pleural cavity which required emergency thorocotomy, reposition of liver and gall bladder into abdominal cavity and repair of diaphragmatic defect by non absorbable sutures.

Isolated traumatic rupture of diaphragm is a very rare entity and our case of isolated traumatic rupture of right hemidiaphragm in a patient with situs inversus is among very rare cases of isolated traumatic diaphragmatic rupture reported in literature.

\section{Conclusion}

Isolated blunt traumatic injuries of diaphragm are very rare and such injuries in a patient with situs inversus are even rarer. Blunt diaphragmatic rupture, usually masked by multiple associated injuries, can lead to serious life threatening surgical complications and there should be a high index of suspicion for diaphragmatic injury in those patients who have suffered a severe thoracoabdominal trauma especially after road traffic collisions. Such patients should be managed as cases of polytrauma and after confirming diagnosis emergency surgical intervention should be performed to restore continuity of thoracic and abdominal cavities.

\section{References}

[1] Benjelloun, E.B., Zahid, F.E., Ousadden, A., Mazaz, K. and Ait Taleb, K. (2008) A Case of Gastric Cancer Associated to Situs Inversus Totalis. Cases Journal, 1, 391. http://dx.doi.org/10.1186/1757-1626-1-391

[2] Akbulut, S., Caliskan, A., Ekin, A. and Yagmur, Y. (2010) Left-Sided Acute Appendicitis with Situs Inversus Totalis: Review of 63 Published Cases and Report of Two Cases. Journal of Gastrointestinal Surgery, 14, 1422-1228. http://dx.doi.org/10.1007/s11605-010-1210-2

[3] Aydin, U., Unalp, O., Yazici, P., Gurcu, B., Sozbilen, M. and Coker, A. (2006) Laparoscopic Cholecystectomy in a Patient with Situs Inversus Totalis. World Journal of Gastroenterology, 12, 7717-7719.

[4] Mansour, K.A. (1997) Trauma to the Diaphragm. Chest Surgery Clinics of North America, 7, 373-383.

[5] Asencio, J.A., Demetriades, D. and Rodriguez, A. (2000) Injury to the Diaphragm. In: Moore, E.E., Mattox, K.L. and Feliciano, D.V., Eds., Trauma. 4th Edition, McGraw-Hill, New York, 603-632.

[6] Mansour, K.A. (1997) Trauma to the Diaphragm. Chest Surgery Clinics of North America, 7, 373-383.

[7] Rosati, C. (1998) Acute Traumatic Injury of the Diaphragm. Chest Surgery Clinics of North America, 8, 371-379.

[8] Boulanger, B.R., Mizman, D.P., Rosati, C. and Rodriguez, A. (1993) A Comparison of Right and Left Blunt Traumatic Diaphragmatic Rupture. Journal of Trauma, 35, 255-260. http://dx.doi.org/10.1097/00005373-199308000-00014

[9] Grimes, O.F. (1974) Traumatic Injuries of the Diaphragm. Diaphragmatic Hernia. American Journal of Surgery, 128, 175-181. http://dx.doi.org/10.1016/0002-9610(74)90090-7 
[10] Gray, S.W., Rowe Jr., J.S. and Skandaliakis, J.E. (1979) Surgical Anatomy of the Gastroesophageal Junction. American Surgeon, 45, 575-587.

[11] Wilson, R.F. and Bender, J.S. (1996) Diaphragmatic Injuries. In: Wilson, R.W. and Walt, A.J., Eds., Management of Trauma, Williams \& Wilkins, Philadelphia, 432-448.

[12] Shah, R., Sabanathan, S., Mearns, A.J. and Choudhury, A.K. (1995) Traumatic Rupture of Diaphragm. Annals of Thoracic Surgery, 60, 1444-1449. http://dx.doi.org/10.1016/0003-4975(95)00629-Y

[13] Matsevych, O.Y. (2008) Blunt Diaphragmatic Rupture: Four Year’s Experience. Hernia, 12, 73-78. http://dx.doi.org/10.1007/s10029-007-0283-7

[14] Vilallonga, R. and Pastor, V. (2011) Right-Sided Diaphragmatic Rupture after Blunt Trauma. An Unusual Entity. World Journal of Emergency Surgery, 6, 3. http://dx.doi.org/10.1186/1749-7922-6-3

[15] Ebrahimi, G. and Bloemers, F.W. (2012) A Delayed Traumatic Right Diaphragmatic Hernia with Hepatothorax. Journal of Surgical Case Reports, 2012, 1. http://dx.doi.org/10.1093/jscr/2012.1.1 